\title{
Transient global amnesia: an intriguing yet benign disturbance
}

\author{
Amnésia global transitória: um transtorno intrigante, embora benigno
}

Leonardo Pantoni ${ }^{1}$

\footnotetext{
1 University of Milan, 'Luigi Sacco' Department of Biomedical and Clinical Sciences, Milan, Italy.

Leonardo Pantoni iD

https://orcid.org/0000-0001-7357-8530

Correspondence:

Leonardo Pantoni; 'Luigi Sacco' Department of Biomedical and Clinical Sciences, University of Milan; Via Giovanni Battista Grassi 74, 20157, Milano, Italy; E-mail: leonardo.pantoni@unimi.it Conflict of interest:

There is no conflict of interest to declare.

Received 20 November 2018 Accepted 01 December 2018

(cc) BY
}

\begin{abstract}
7 he paper by Alessandro et al., published in this issue of Arquivos de NeuroPsiquiatria $^{1}$, reports on the results of a study aimed at identifying possible predictors of episode recurrence in a group of 203 transient global amnesia (TGA) patients seen in one center over a relatively short time period.
\end{abstract}

As in previous studies, only a minority of patients had a recurrence over the two-year follow up; the low rate of recurrence ( $8 \%$ ) was comparable to that reported in other studies with longer follow ups ${ }^{2}$. Overall, about one-quarter of TGA patients will experience a second attack in their lifetime, with very few experiencing more than two ${ }^{3}$. The authors found that patients with recurrent TGA more frequently had a history of migraine than TGA patients without recurrence ${ }^{1}$. Of note, this difference was statistically significant but, by looking at the actual figures (migraine was present in $37.5 \%$ of patients with recurrence and in $14 \%$ of those without recurrence), one can recognize that this factor did not play a crucial role in pathogenic terms, being present in only one-third of patients with recurrent TGA. None of the other many clinical characteristics and complementary studies looked at, including MRI and venous Doppler studies, were predictors of an increased risk of recurrence ${ }^{1}$.

Transient global amnesia was first described by the eminences Fisher and Adams in $1964^{4}$. Framing of the concept and specific criteria were later introduced by Hodges and Warlow in $1990^{5}$. Since then, the interest of clinicians and researchers has always been directed toward the possible etiology and mechanisms of the disturbance, also because TGA itself does not generate other great demands, as the episodes are self-limiting in less than 24 hours (usually few hours) and do not require any specific therapeutic intervention.

Since the first TGA patient series description, three main pathogenic hypotheses have been advanced. The first one equated TGA to transient ischemic attacks (TIA), the second hypothesized the presence of seizure discharge during TGA, the third one considered migraine as relevant to TGA development ${ }^{6}$. None of these three hypotheses has been successively confirmed. For example, the prognosis of TGA is clearly different from that of TIA patients ${ }^{2,7}$ and TGA is not a risk factor for stroke. Definite EEG epileptic activities have never been documented in large series of TGA patients, either acutely or after the episode, once the precise Hodges and Warlow diagnostic criteria had been applied; and patients with TGA, which typically occurs in late life, do not develop epilepsy. The fact that migraine is somehow more prevalent in TGA patients than in controls is an observation reported by many series ${ }^{7}$ but remains difficult to interpret, particularly considering that TGA typically occurs in late life and as a single event in most patients.

The association of some TGA episodes with Valsalva-like maneuvers has more recently generated a fourth hypothesis, i.e., a role for internal jugular valve insufficiency ${ }^{8}$, but this hypothesis has also not been confirmed ${ }^{9}$

A large number of studies, such as the one by Alessandro et al. ${ }^{1}$, have reported a remarkable temporal association between TGA episodes and what have been defined as precipitating events, such as exertion, hot or cold baths, quarrels, and Valsalva-like maneuvers such as coughing. Most surprising is the occurrence of a considerable number of TGA episodes soon after sexual intercourse. In our original series, this was the most frequent precipitating factor ${ }^{2}$. It should be pointed out that this association must specifically be investigated by clinicians 
but it is not always immediately reported by TGA patients because of shame or even restraint, as some intercourse happened in extra-conjugal situations.

The lack of evidence for a truly organic origin of TGA and the observation of the association of TGA episodes with events with psychological weight led us to investigate the role of psychogenic factors in $\mathrm{TGA}^{3}$. In our series of TGA patients, we found that almost half of the precipitating events were possibly related to emotionally stressful or phobogenic situations, and that TGA patients had higher phobic attitudes on a specific scale in comparison with a control group of TIA patients. On the other hand, in a focused analysis, the amount of stressful life events in the year that preceded the attack did not differ between the case patients with TGA and the control patients with TIA. In the same patient series, compared with TIA controls, TGA patients more frequently had a personal and family history of psychiatric diseases and of alcohol use ${ }^{2}$.

Despite our studies and our hypotheses supporting, in some way, the benign nature of the disease, they still do not explain why there is a single episode in most cases, whereas one would expect a higher recurrence rate if a psychogenic mechanism was the basis of the event.

Thus, the mystery around TGA continues, and the disturbance remains globally ineffable and inexplicable. In summary, we are faced with something that: 1) usually occurs in late life; 2) is mono-episodic in most patients; 3) is self-limiting; 4) does not imply an increased risk of stroke, epilepsy, or dementia; 5) often occurs after precipitating events that are, however, difficult to loop together to lead to a common mechanism; and 6) is perhaps more frequent in patients with a phobogenic personality trait.

Nowadays, TGA remains an intriguing manifestation that should, however, be considered benign. In this sense, patients must be reassured that they do not require additional investigations or specific treatment. However, the interest of neurologists in TGA remains high because the understanding of TGA etiopathogenesis may help our comprehension of memory mechanisms and memory dysfunctions.

\section{References}

1. Alessandro L, Calandri IL, Suarez MF, Heredia ML, Chaves H, Allegri RF, Farez M. Transient global amnesia: clinical features and prognostic factors suggesting recurrence. Arq Neuropsiquiatr 2019;77(1):3-9. https://doi.org/10.1590/0004-282X20180157

2. Pantoni L, Bertini E, Lamassa M, Pracucci G, Inzitari D. Clinical features, risk factors, and prognosis in transient global amnesia: a follow-up study. Eur J Neurol. 2005 May;12(5):350-6. https://doi.org/10.1111/j.1468-1331.2004.00982.x-

3. Inzitari D, Pantoni L, Lamassa M, Pallanti S, Pracucci G, Marini P. Emotional arousal and phobia in transient global amnesia. Arch Neurol. 1997 Jul;54(7):866-73. https://doi.org/10.1001/archneur.1997.00550190056015-

4. Fisher CM, Adams RD. Transient global amnesia. Acta Neurol Scand Suppl. 1964;40 suppl.9:9.

5. Hodges JR, Warlow CP. Syndromes of transient amnesia: towards a classification. A study of 153 cases. J Neurol Neurosurg Psychiatry. 1990 Oct;53(10):834-43. https://doi.org/10.1136/jnnp.53.10.834
6. Pantoni L, Lamassa M, Inzitari D. Transient global amnesia: a review emphasizing pathogenic aspects. Acta Neurol Scand. 2000 Nov;102(5):275-83. https://doi.org/10.1034/j.1600-0404.2000.102005275.x

7. Zorzon M, Antonutti L, Masè G, Biasutti E, Vitrani B, Cazzato G. Transient global amnesia and transient ischemic attack. Natural history, vascular risk factors, and associated conditions. Stroke. 1995 Sep;26(9):1536-42. https://doi.org/10.1161/01.STR.26.9.1536

8. Sander K, Sander D. New insights into transient global amnesia: recent imaging and clinical findings. Lancet Neurol. 2005 Jul;4(7):437-44. https://doi.org/10.1016/S1474-4422(05)70121-6

9. Baracchini C, Tonello S, Farina F, Viaro F, Atzori M, Ballotta E, et al. Jugular veins in transient global amnesia: innocent bystanders. Stroke. 2012 Sep;43(9):2289-92. https://doi.org/10.1161/STROKEAHA.112.654087 